\title{
Screening for pulmonary arterial hypertension in adults carrying a BMPR2 mutation
}

\author{
David Montani $\mathbb{1}^{1,2,3,14}$, Barbara Girerd ${ }^{1,2,3,14}$, Xavier Jaïs ${ }^{1,2,3}$, Pierantonio Laveneziana ${ }^{4,5}$, \\ Edmund M.T. Lau ${ }^{6}$, Amir Bouchachi ${ }^{3,7}$, Sébastien Hascoët $\mathbb{C}^{3,8}$, Sven Günther ${ }^{9}$, Laurent Godinas ${ }^{1,2,3}$, \\ Florence Parent ${ }^{1,2,3}$, Christophe Guignabert $\mathbb{1}^{1,3}$, Antoine Beurnier ${ }^{3,10}$, Denis Chemla ${ }^{3,10}$, \\ Philippe Hervé ${ }^{3,11}$, Mélanie Eyries ${ }^{12,13}$, Florent Soubrier $\mathbb{C}^{12,13}$, Gérald Simonneau ${ }^{1,2,3}$, Olivier Sitbon $\mathbb{C}^{1,2,3}$, \\ Laurent Savale (10) ${ }^{1,2,3}$ and Marc Humbert $\mathbb{( i )}^{1,2,3}$
}

\begin{abstract}
${ }^{1}$ School of Medicine, Université Paris-Saclay, Le Kremlin-Bicêtre, France. ${ }^{2}$ Service de Pneumologie et Soins Intensifs Respiratoires, AP-HP, Hôpital Bicêtre, Le Kremlin-Bicêtre, France. ${ }^{3}$ INSERM UMRS 999, Hôpital Marie Lannelongue, Le Plessis-Robinson, France. ${ }^{4}$ INSERM UMRS 1158, Neurophysiologie Respiratoire Expérimentale et Clinique, Sorbonne Université, Paris, France. "Service des Explorations Fonctionnelles de la Respiration, de l'Exercice et de la Dyspnée, Département Médico-Universitaire "APPROCHES", Hôpitaux Universitaires Pitié-Salpêtrière, Tenon et Saint-Antoine, AP-HP, Sorbonne Université, Paris, France. ${ }^{6}$ Dept of Respiratory Medicine, Royal Prince Alfred Hospital, Camperdown, Australia. ${ }^{7}$ Service de Cardiologie, AP-HP, Hôpital Bicêtre, Le Kremlin-Bicêtre, France. ${ }^{8}$ Pôle de Cardiologie Pédiatrique et Congénitale, Hôpital Marie Lannelongue, Le Plessis-Robinson, France. ${ }^{9}$ Service de Physiologie, AP-HP, Georges Pompidou European Hospital, Paris, France. ${ }^{10}$ Service de Physiologie, AP-HP, Hôpital Bicêtre, Le Kremlin-Bicêtre, France. ${ }^{11}$ Service de Chirurgie Thoracique, Hôpital Marie Lannelongue, Le Plessis-Robinson, France. ${ }^{12}$ Département de Génétique, AP-HP, Hôpital Pitié-Salpêtrière, Paris, France. ${ }^{13}$ INSERM UMRS 1166, Sorbonne Université and Institute for Cardiometabolism and Nutrition (ICAN), Paris, France. ${ }^{14}$ These two authors contributed equally to this work.
\end{abstract}

Corresponding author: Marc Humbert (marc.humbert@aphp.fr)

Copyright $\odot$ The authors 2021. For reproduction rights and permissions contact permissions@ersnet.org

This article is open access and distributed under the terms of the Creative Commons Attribution Non-Commercial Licence 4.0.

This article has supplementary material available from erj. ersjournals.com

This article has an editorial commentary: https://doi.org/ 10.1183/13993003.00286-2021

Received: 18 Nov 2020 Accepted: 17 Dec 2020

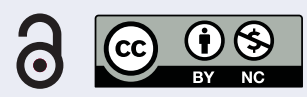

Shareable abstract (@ERSpublications)

Asymptomatic BMPR2 mutation carriers have a $2.3 \%$ per year risk of developing PAH. DELPHI-2 provides the platform for future international multicentre studies to refine multimodal screening algorithms in BMPR2 mutation carriers. http://bit.ly/3oi2KJ1

Cite this article as: Montani D, Girerd B, Jaïs X, et al. Screening for pulmonary arterial hypertension in adults carrying a BMPR2 mutation. Eur Respir J 2021; 58: 2004229 [DOI: 10.1183/13993003.04229-2020].

\section{Abstract}

Background Heritable pulmonary arterial hypertension (PAH) is most commonly due to heterozygous mutations of the BMPR2 gene. Based on expert consensus, guidelines recommend annual screening echocardiography in asymptomatic BMPR2 mutation carriers. The main objectives of this study were to evaluate the characteristics of asymptomatic BMPR2 mutation carriers, assess their risk of occurrence of $\mathrm{PAH}$ and detect PAH at an early stage in this high-risk population.

Methods Asymptomatic BMPR2 mutation carriers underwent screening at baseline and annually for a minimum of 2 years (DELPHI-2 study; ClinicalTrials.gov: NCT01600898). Annual screening included clinical assessment, ECG, pulmonary function tests, 6-min walk distance, cardiopulmonary exercise testing, chest radiography, echocardiography and brain natriuretic peptide (BNP) or N-terminal (NT)proBNP level. Right heart catheterisation (RHC) was performed based on predefined criteria. An optional RHC at rest and exercise was proposed at baseline.

Results 55 subjects (26 males; median age 37 years) were included. At baseline, no PAH was suspected based on echocardiography and NT-proBNP levels. All subjects accepted RHC at inclusion, which identified two mild PAH cases (3.6\%) and 12 subjects with exercise pulmonary hypertension (21.8\%). At long-term follow-up (118.8 patient-years of follow-up), three additional cases were diagnosed, yielding a PAH incidence of $2.3 \%$ per year (0.99\% per year in males and 3.5\% per year in females). All PAH cases remained at low-risk status on oral therapy at last follow-up.

Conclusions Asymptomatic BMPR2 mutation carriers have a significant risk of developing incident PAH. International multicentre studies are needed to confirm that refined multimodal screening programmes with regular follow-up allow early detection of PAH. 
Introduction

Pulmonary arterial hypertension (PAH) is a rare condition with a prevalence of 15-60 per million, affecting the small pulmonary arteries leading to right ventricular failure [1-3]. Due to its rarity and nonspecific clinical presentation, PAH is usually diagnosed late in the course of the disease [1]. Despite the recent approval of targeted drugs, PAH remains a disease associated with a poor prognosis with a median survival of only 7 years in the current era [2, 4].

Mutations of the BMPR2 gene (encoding bone morphogenetic protein receptor type 2) have been identified as the most common cause of heritable PAH. PAH due to BMPR2 mutation is an autosomal dominant disorder with incomplete penetrance (estimated at $42 \%$ in females and $14 \%$ in males) [5] and has a worse prognosis compared with idiopathic PAH [6-8]. Genetic counselling and testing has become an integral part of PAH care, and allows screening for mutations in PAH-predisposing genes in patients as well as carrier detection in asymptomatic relatives [6-8].

Studies have shown that PAH therapy instituted at an early stage translates to better long-term outcomes [9-11]. Therefore, it seems essential to establish early diagnosis, particularly in high-risk populations such as BMPR2 mutation carriers [2, 4]. In the absence of robust evidence, the European Society of Cardiology/ European Respiratory Society (ESC/ERS) guidelines recommend that asymptomatic BMPR2 mutation carriers may be offered annual screening Doppler echocardiography for the early detection of PAH [2, 4]. However, this recommendation is based on expert consensus, since no screening strategy has ever been evaluated for this population [2, 4]. Furthermore, no previous study has assessed the risk of incident PAH in BMPR2 mutation carriers using a longitudinal follow-up design.

The main objectives of the present longitudinal study (DELPHI-2) were to 1) assess the risk of occurrence of PAH in BMPR2 mutation carriers; 2) determine their clinical, functional, biological, echocardiographic and haemodynamic characteristics; 3) determine predictive factors for the development of $\mathrm{PAH}$; and 4) detect PAH at an early stage and offer timely management.

Methods

Subjects

Genetic counselling and screening of mutations in PAH-predisposing genes are offered to all patients with idiopathic or familial PAH followed at the French Referral Centre for Pulmonary Hypertension and subsequently to their at-risk relatives when a mutation has been identified [12]. The DELPHI-2 study (Screening of PAH in BMPR2 mutation carriers; ClinicalTrials.gov: NCT01600898) was approved by the Institutional Ethics Committee on 25 November 2011 (CPP-IDF-VII; approval 11-028). From March 2012 to October 2014, asymptomatic relatives carrying a BMPR2 mutation were offered inclusion in the DELPHI-2 study with a minimum follow-up of 2 years (figure 1). Details of the relatives of heritable PAH patients and methods of screening and genetic testing (confirmation on two independent tests of BMPR2 mutations) have been previously reported in the experience of genetic counselling in the French Referral Centre for Pulmonary Hypertension [12]. Inclusion criteria were age $\geqslant 18$ years and all subjects were asymptomatic in New York Heart Association Functional Class (NYHA FC) I at inclusion. Subjects with other known conditions associated with PAH (connective tissue disease, portal hypertension, HIV infection, schistosomiasis and congenital heart disease with the exception of atrial septal defect) or pulmonary hypertension (chronic respiratory disease, left heart disease, chronic thromboembolic disease and sickle cell disease) at inclusion were excluded. The other exclusion criteria were adults under guardianship, persons deprived of liberty, in emergency situations, persons who refused or were unable to give informed consent and subjects without affiliation to a regime of social insurance. Females pregnant at inclusion were not eligible.

\section{Study design}

Initial evaluation included medical and occupational history, and a questionnaire on prior exposure to drugs and toxins. Assessment at initial and subsequent yearly visits included physical examination, functional assessment by NYHA FC, ECG, chest radiography, nonencouraged 6-min walk distance (6MWD), pulmonary function tests (PFTs), cardiopulmonary exercise testing (CPET), Doppler echocardiography and brain natriuretic peptide (BNP) or N-terminal (NT)-proBNP plasma levels. RHC at rest and exercise was proposed to each participant at inclusion as an optional investigation [1, 13, 14]. ECG, Doppler echocardiography, PFTs and CPET were reviewed by two experts blinded to the results of RHC and other examinations. An investigational CPET probability score of pulmonary hypertension was predefined based on five criteria adapted from data published by our group and others (supplementary table S1) [15-20]. Complete methodological descriptions of all investigations are presented in the supplementary methods. 


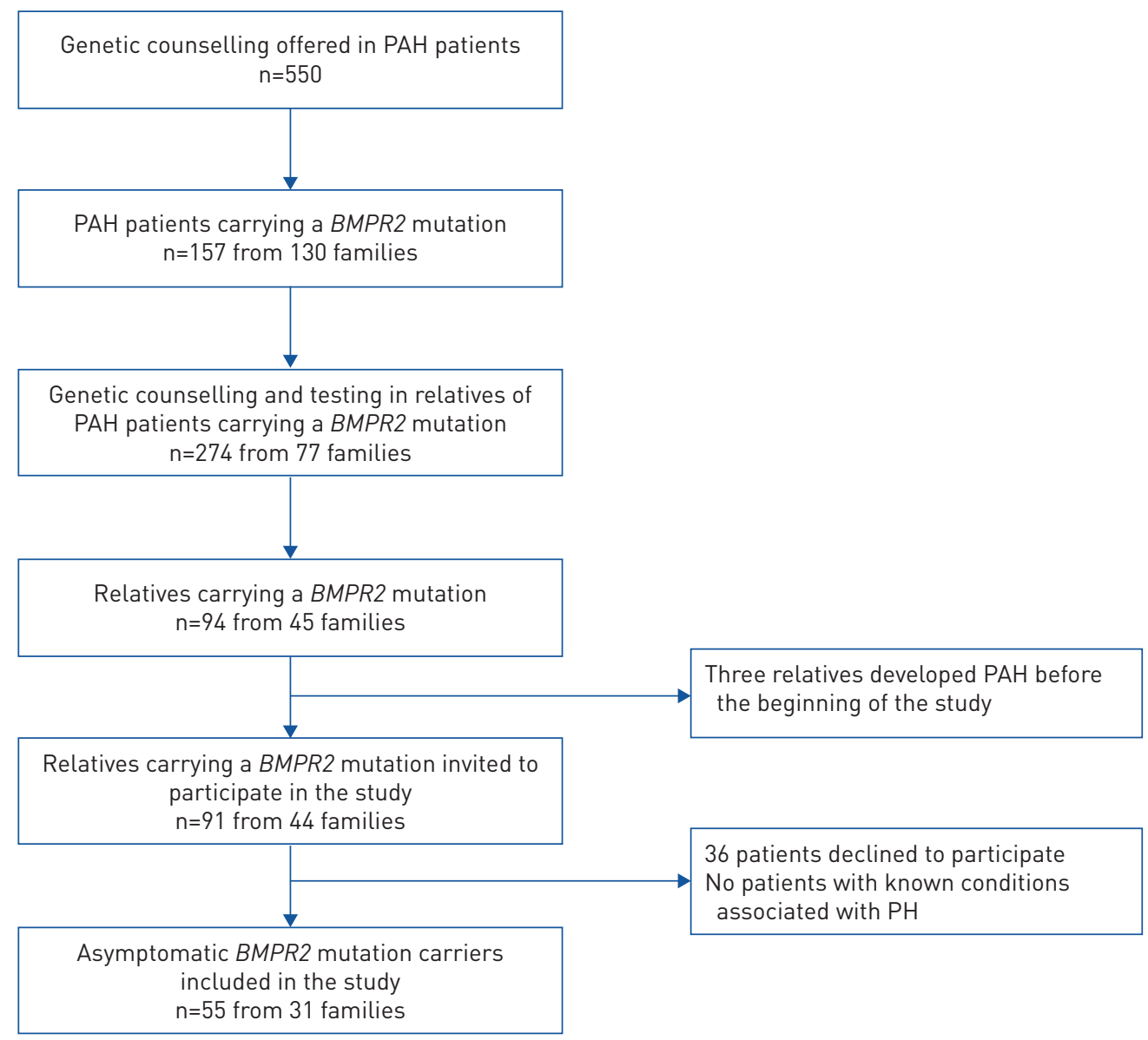

FIGURE 1 Flowchart of DELPHI-2. PAH: pulmonary arterial hypertension; PH: pulmonary hypertension.

During the study, subjects were asked to contact the study team for an urgent assessment in case of unexplained dyspnoea, malaise or syncope. RHC was indicated if subjects presented with at least one of the following criteria: 1) clinical signs suggestive of PAH (unexplained dyspnoea with worsened NYHA FC, malaise or syncope), 2) tricuspid regurgitation velocity (TRV) $\geqslant 2.8 \mathrm{~m} \cdot \mathrm{s}^{-1}$ at Doppler echocardiography, or 3) decrease in oxygen consumption at CPET corrected for body weight at peak exercise $\left(V_{\mathrm{O}_{2}}^{\prime}\right)>20 \%$ compared with reference value at inclusion or between two consecutive evaluations. $\mathrm{PAH}$ was confirmed if RHC showed mean pulmonary arterial pressure (mPAP) $\geqslant 25 \mathrm{mmHg}$ with pulmonary arterial wedge pressure (PAWP) $\leqslant 15 \mathrm{mmHg}$ and pulmonary vascular resistance (PVR) $\geqslant 3 \mathrm{WU}$ on RHC at rest. If pre-capillary pulmonary hypertension was diagnosed during the study, patients were managed as recommended by ESC/ERS guidelines [2] with a complete work-up (including computed tomography (CT) pulmonary angiography, high-resolution chest CT, ventilation/perfusion lung scan, abdominal ultrasound, HIV serology and immunological tests) to exclude other causes of pulmonary hypertension. Abnormal haemodynamics at exercise (“exercise pulmonary hypertension”) was defined by mPAP >30 mmHg and total pulmonary resistance (TPR) >3 WU [1, 21].

At the end of the initial mandatory 2-year phase of DELPHI-2, an optional long-term extension follow-up with the same design was proposed to all subjects. If subjects declined, an annual phone call was proposed and subjects were informed to contact the study team urgently in case of dyspnoea, malaise or syncope. If pregnancy occurred during follow-up, a specific follow-up was proposed with monthly Doppler echocardiography during the second and third trimesters followed by a complete assessment within 3 months of delivery.

Subjects diagnosed with PAH were included in the French Pulmonary Hypertension Registry according to the requirements of the Commission Nationale Informatique et Liberté (approval 842063) [22]. PAH 
patients were risk stratified using the REVEAL 2.0 score, the ESC/ERS guidelines risk stratification tool and the simplified French PAH risk assessment [2, 22, 23].

\section{Statistical analysis}

Continuous data were presented as median (minimum-maximum range) and categorical data were presented as number (percentage). We used the Mann-Whitney test to compare data between subjects with or without PAH. The Chi-squared test with Yates correction if needed was used to compare categorical data. We considered a p-value $<0.05$ as significant. Event-free survival (time to death or lung transplantation) analysis for index cases of patients included in DELPHI-2 was performed from the time of the first diagnosis of PAH confirmed by RHC and survival was estimated by the Kaplan-Meier method. We performed statistical analysis with StatView version 5.0 (SAS Institute, Cary, NC, USA) and Prism (GraphPad, La Jolla, CA, USA).

\section{Results}

\section{Study population}

At the end of the inclusion period (1 October 2014), genetic counselling had been offered to $550 \mathrm{PAH}$ patients, of whom 157 patients from 130 families carried a BMPR2 mutation (figure 1). Asymptomatic carrier detection had been performed in 274 relatives of these 157 patients. 94 relatives from 45 families carried a BMPR2 mutation. Three relatives (two females and one male) developed symptomatic PAH before the beginning of the study. In total, 55 BMPR2 mutation carriers (from 31 families) were enrolled in DELPHI-2 from 1 March 2012 to 1 October 2014, followed by a minimum follow-up of 2 years (figure 2). During the 2-year mandatory follow-up period, 144 visits were performed as part of DELPHI-2 (100.9 patient-years of follow-up). The BMPR2 mutations from our cohort subjects are presented in supplementary table S2, including 14 families with nonsense mutations, 10 families with missense mutations and seven families with large rearrangements previously reported by GIRERD et al. [12]. Median

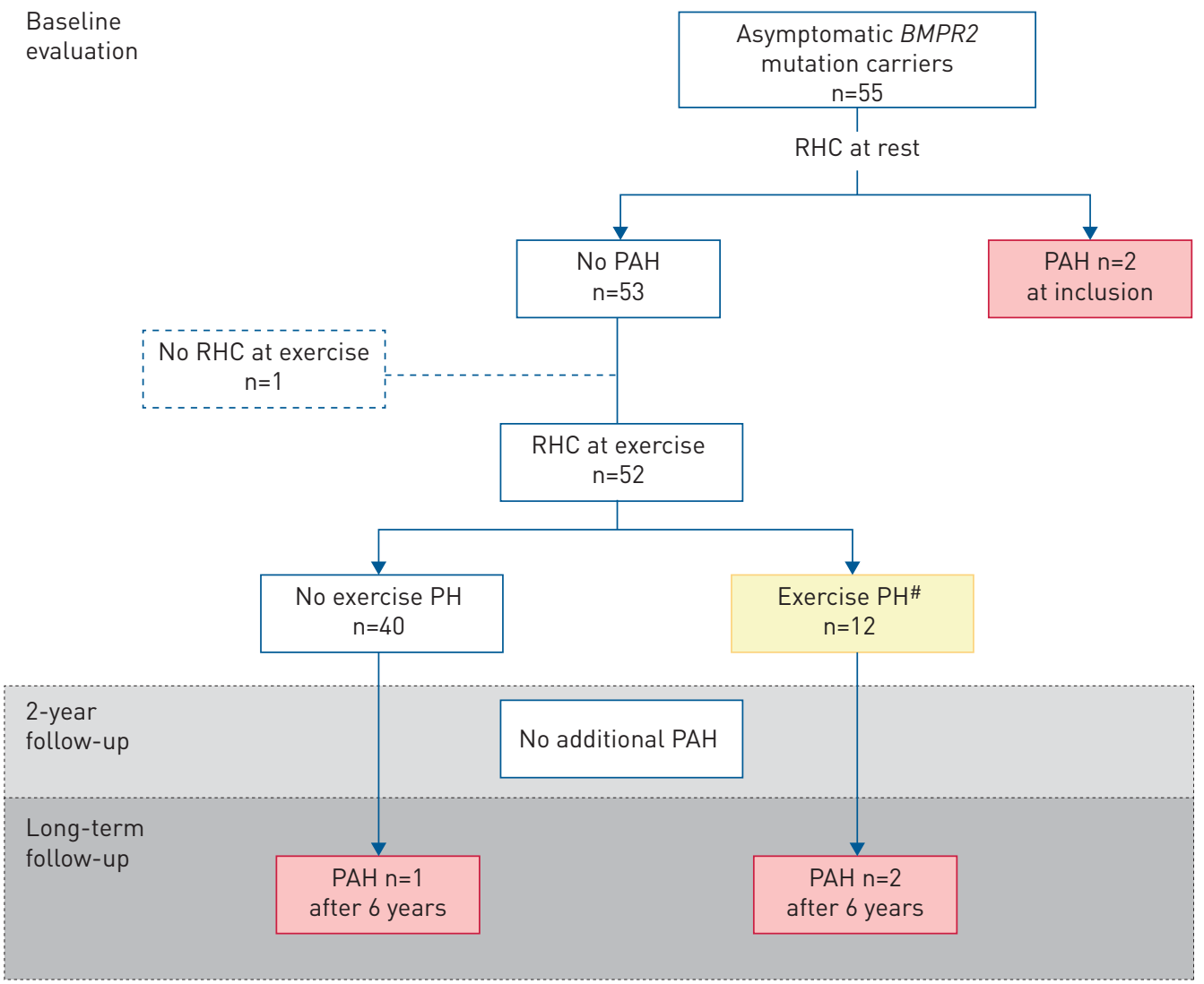

FIGURE 2 Baseline evaluation and follow-up of the 55 asymptomatic BMPR2 mutation carriers. PAH: pulmonary arterial hypertension; RHC: right heart catheterisation; $\mathrm{PH}$ : pulmonary hypertension. ": defined as mean pulmonary arterial pressure $>30 \mathrm{mmHg}$ and total pulmonary resistance $>3 \mathrm{WU}$. 
(range) age at inclusion was 37 (18-78) years and the sex ratio was 0.9 (26 males). 19 subjects (35\%) had a smoking history $>5$ pack-years, 11 (20\%) had systemic hypertension, four (7\%) had type 2 diabetes, three (5\%) had dyslipidaemia, two had a history of chemotherapy for breast cancer or lymphoma, one had lumbar disc hernia and one had a past history of pacemaker implantation for sinus node dysfunction. Clinical characteristics are presented in table 1 and supplementary table S3.

\section{Evaluation at baseline}

ECG, chest radiography and biological tests

ECG was normal or with no significant abnormalities in 44 subjects (80\%), including one paced rhythm. Two ECGs were inconclusive with isolated left axis deviation. Nine (16.3\%) subjects had ECG with incomplete right bundle branch block $(n=5)$ or signs of right ventricular hypertrophy including inverted T-waves in the right pre-cordial leads $(n=4)$ and/or right axis deviation $(n=1)$. No abnormalities were found in chest radiography. BNP/NT-proBNP, creatinine and uricaemia were in the normal range in all subjects (table 1 and supplementary table S3). Uricaemia was significantly associated with $\operatorname{sex}(\mathrm{p}<0.0001)$ and body mass index $(\mathrm{p}<0.05)$, but was not different between patients with or without PAH.

PFTS and CPET

At inclusion, all subjects were in NYHA FC I. Median (range) 6MWD was 533 (368-693) m. Results of PFTs $(n=55)$ and CPET ( $n=54$, not performed in one relative because of lumbar disc herniation) were expressed as percentage of predicted value. Median (range) $\mathrm{FEV}_{1}$ was $105 \%$ (69-152\%) and FVC was $108 \%$ (75-162\%). Median (range) diffusing capacity of the lung for carbon monoxide $\left(D_{\mathrm{LCO}}\right)$ and $D_{\mathrm{LCO}} /$ $V_{\mathrm{A}}$ were $75.5 \%$ (39-126\%) and 88\% (49-126\%), respectively (table 1 and supplementary table S3).

During CPET (table 1), the median (range) workload was 120 (42-279) W. At peak exercise, median (range) percentage predicted $V_{\mathrm{O}_{2}}^{\prime}$ at peak was $81 \%$ (47-132\%). Median (range) dead space fraction $\left(V_{\mathrm{D}} /\right.$ $V_{\mathrm{T}}$ ) was $0.21(0.06-0.39)(\mathrm{n}=52)$. Based on the investigational CPET probability score of pulmonary hypertension (table 1), 31 (57.4\%) subjects were classified as "unlikely", 21 (38.9\%) subjects as "possible", one subject as "likely" and one as "very likely” (table 2).

Doppler echocardiography

Doppler echocardiography was performed with blinding of the results of RHC or other examinations at inclusion and follow-up. A measurable TRV was obtained in 30 subjects (54.5\%) and was $<2.8 \mathrm{~m} \cdot \mathrm{s}^{-1}$ in all cases (median (range) $2.0(1.5-2.75) \mathrm{m} \cdot \mathrm{s}^{-1}$ ). Median (range) right atrial surface area was 13.0 (7.7$27.0) \mathrm{cm}^{2}$. Median (range) diastolic right ventricle surface area was $16.9(8.0-28.0) \mathrm{cm}^{2}$ and systolic right ventricle surface area was $9.5(3.7-15.0) \mathrm{cm}^{2}$. Median (range) TAPSE was $23(16-28) \mathrm{mm}$. No pericardial effusion was reported. All results are presented in table 1 and supplementary table S3. PAH was not suspected in any subjects based on Doppler echocardiography results at baseline. An atrial septal defect (ostium secundum) of $10 \mathrm{~mm}$ was detected in one subject.

Haemodynamic evaluation at rest

All subjects $(n=55)$ accepted the optional RHC at inclusion. This identified two asymptomatic subjects with mild PAH (figure 2). Haemodynamic characteristics of the 53 subjects without PAH and of the two PAH patients diagnosed at inclusion (patients 1 and 2) are presented in table 1. Distributions of mPAP and PVR are presented in figure 3. One subject with uncontrolled systemic hypertension at inclusion had post-capillary pulmonary hypertension. Repeat RHC after treatment of systemic hypertension demonstrated haemodynamic normalisation.

\section{Haemodynamic evaluation at exercise}

52 out of the 53 subjects without PAH at inclusion performed RHC at exercise. 12 of them (23\%) had exercise pulmonary hypertension, as defined by $\mathrm{mPAP}>30 \mathrm{mmHg}$ and TPR $>3 \mathrm{WU}$ (figure 2). Subjects who experienced exercise pulmonary hypertension were significantly older (median 57.8 versus 26.9 years; $\mathrm{p}<0.0001$ ) and had significant differences in haemodynamics at rest (higher mPAP, PVR and TPR, and lower cardiac index, PAWP and stroke volume index) compared with patients with normal haemodynamics at exercise (table 3). Of note, one patient had an increased PVR $>3 \mathrm{WU}$ but normal mPAP $16 \mathrm{mmHg}$ at baseline. Exercise haemodynamics showed exercise pulmonary hypertension with mPAP $39 \mathrm{mmHg}$ and TPR 5.0 WU, associated with a decrease in PVR (2.3 WU) and an increase in PAWP (21 mmHg), suggesting the absence of pulmonary vascular disease but possible heart failure with preserved ejection fraction. 
TABLE 1 Characteristics of BMPR2 mutation carriers without pulmonary arterial hypertension (PAH) and patients diagnosed with PAH in DELPHI-2 and long-term follow-up

DELPHI-2 ( $n=55)$

Long-term follow-up $(n=36)$

$\begin{array}{llllll}\text { No PAH at inclusion }(n=53) & \text { Patient } 1 & \text { Patient } 2 & \text { Patient } 3 & \text { Patient } 4 & \text { Patient } 5\end{array}$

\begin{tabular}{|c|c|c|c|c|c|c|}
\hline \multicolumn{7}{|l|}{ Demographic data } \\
\hline Age years & 37.1 (18-67.5); (24.9-49.7) & 25.5 & 78.1 & 49.9 & 72.5 & 46.8 \\
\hline Male/female & $26 / 27$ & Female & Female & Female & Female & Male \\
\hline Tobacco exposure $>5$ pack-years & $18(34)$ & Yes & No & No & No & Yes \\
\hline $\mathrm{BMI} \mathrm{kg} \cdot \mathrm{m}^{-2}$ & 22.5 (16.8-32.2); (21.7-26.1) & 22.0 & 25.2 & 22.9 & 21.3 & 24.9 \\
\hline Systemic hypertension & $10(19)$ & No & Yes & No & No & No \\
\hline Diabetes & $3(6)$ & No & Yes & No & No & No \\
\hline Dyslipidaemia & $3(6)$ & No & No & No & No & No \\
\hline $\begin{array}{l}\text { Delay between symptoms and } \\
\text { diagnosis months }\end{array}$ & NA & NA & NA & 3 & NA & $3-6$ \\
\hline Potential additional risk factor & NA & Pregnancy & None & Chemotherapy & Chemotherapy & None \\
\hline \multicolumn{7}{|l|}{ Functional parameters } \\
\hline NYHA FC I-IV & 1 & 1 & 1 & II & 1 & II \\
\hline 6MWD m & 539 (368-693); (486-599) & 533 & 420 & 397 & 412 & 505 \\
\hline $\mathrm{FEV}_{1} \%$ pred & 105 (69-141); (97-113) & 86 & 152 & 91 & 119 & 91 \\
\hline FVC $\%$ pred & 108 (75-140); (98-117) & 89 & 162 & 103 & 144 & 96 \\
\hline$D_{\text {LCO }} \%$ pred & 76 (39-126); (69-87) & 50 & 63 & 42 & 52 & 82 \\
\hline$D_{\mathrm{LCO}} / V_{\mathrm{A}} \%$ pred & 89 (49-126); (74-100) & 62 & 66 & 65 & 58 & 104 \\
\hline \multicolumn{7}{|l|}{ CPET } \\
\hline$V^{\prime} \mathrm{O}_{2}$ at peak $\%$ pred & 81 (47-132); (65.5-91.5) & 70 & 89 & 58 & 81 & 62 \\
\hline$V_{E}^{\prime}$ at peak $\%$ pred & 76.2 (37.8-156.8); (56.7-101.8) & 74 & 53.9 & 63.3 & 63.5 & 72.4 \\
\hline$V_{\mathrm{D}} / V_{\mathrm{T}}$ & $0.21(0.06-0.39) ;(0.12-0.24)$ & 0.15 & 0.27 & 0.53 & 0.49 & NA \\
\hline$V_{E}^{\prime} / V_{\mathrm{CO}_{2}}^{\prime}$ at anaerobic threshold & 33 (24-66); (23.5-45) & 36 & 54 & 59 & 43 & 39 \\
\hline$V_{\mathrm{O}_{2}}^{\prime} / \mathrm{HR} \%$ pred & 88 (50-125); (77.5-101) & 100 & 98 & 60 & 122 & 78 \\
\hline$P_{\mathrm{aO}_{2}}$ at rest $\mathrm{mmHg}$ & 93 (75-118); (85-100) & 99 & 70 & 70 & 94 & 63 \\
\hline$P_{\mathrm{aO}_{2}}$ at peak $\mathrm{mmHg}$ & 106 (85-124); (97.5-114) & NA & 97 & 49 & 83 & NA \\
\hline$P_{(\mathrm{A}-\mathrm{a}) \mathrm{O}_{2}} \mathrm{mmHg}$ & $12.7(-5.6-32.8) ;(7.7-19.8)$ & 15.7 & 26 & 77 & 40 & NA \\
\hline CPET probability score & $2(0-6)$ & 4 & 9 & 10 & 8 & NA \\
\hline \multicolumn{7}{|l|}{ Echocardiography } \\
\hline $\mathrm{TRV} \mathrm{m} \cdot \mathrm{s}^{-1}$ & $2(1.5-2.75)^{\#} ;(1.85-2.3)$ & 2 & 2.65 & 4.2 & 3.3 & 4.4 \\
\hline RA surface area $\mathrm{cm}^{2}$ & 13.0 (7.7-27.0); (10-15) & 15 & 14 & 19 & 16 & 21 \\
\hline LA surface area $\mathrm{cm}^{2}$ & 14 (9.5-23); (12.5-17) & 15 & 9 & 12 & 17 & 13 \\
\hline Diastolic RV surface area $\mathrm{cm}^{2}$ & 17.5 (8.0-28.0); (14-20) & 15.6 & 16 & 22.9 & 15.8 & 25 \\
\hline Systolic RV surface area $\mathrm{cm}^{2}$ & 9.5 (3.7-15.0); (7-11) & 11 & 8 & 14.8 & 8.2 & 12 \\
\hline RVEF \% & 45 (30-71); (40-50) & 30 & 50 & 35 & 48 & 50 \\
\hline TAPSE $\mathrm{mm}$ & 23 (16-28); (21-25) & 25 & 16 & 23 & 19 & 21 \\
\hline RV Tei index & $0.24(0.06-0.77) ;(0.18-0.30)$ & NA & NA & 0.2 & NA & 0.47 \\
\hline \multicolumn{7}{|l|}{ Haemodynamics } \\
\hline $\mathrm{mPAP} \mathrm{mmHg}$ & 14 (8-23); (13-17) & 26 & 25 & 43 & 29 & 50 \\
\hline PAWP $\mathrm{mmHg}$ & $8(2-14) ;(6-10)$ & 8 & 7 & 7 & 5 & 8 \\
\hline Cardiac output L.min ${ }^{-1}$ & 6.03 (3.77-10.33); (5.30-7.00) & 7.27 & 4.05 & 3.93 & 3.27 & 4.57 \\
\hline Cardiac index $\mathrm{L} \cdot \mathrm{min}^{-1} \cdot \mathrm{m}^{-2}$ & $3.50(2.20-5.44) ;(3.11-4.10)$ & 4.38 & 2.8 & 2.31 & 1.94 & 2.36 \\
\hline $\mathrm{SVI} \mathrm{mL} \cdot \mathrm{m}^{-2}$ & $51.6(33.7-79.2) ;(43.6-53.5)$ & 55.4 & 35.0 & 46.8 & 32.3 & 31.9 \\
\hline TPR WU & $2.5(1.2-4.8) ;(1.9-3.0)$ & 3.58 & 6.17 & 10.93 & 8.88 & 10.95 \\
\hline PVR WU & $1.0(0.2-3.7) ;(0.7-1.4)$ & 2.5 & 4.4 & 9.2 & 7.3 & 9.2 \\
\hline Acute vasodilator test & Not performed & Negative & Negative & Negative & Negative & Negative \\
\hline \multicolumn{7}{|l|}{ Biological tests } \\
\hline Uricaemia $\mu \mathrm{mol} \cdot \mathrm{L}^{-1}($ normal $<357)$ & 286 (170-528); (231-374) & 250 & 465 & 306 & 270 & 603 \\
\hline BNP ng $\cdot \mathrm{L}^{-1}($ normal $<80)$ & $11(5-60) ;(8.8-15.5)$ & 9 & 19 & NA & NA & NA \\
\hline NT-proBNP ng.L $\mathrm{L}^{-1}$ (normal <300) & NA & NA & NA & 484 & 252 & 437 \\
\hline \multicolumn{7}{|c|}{ 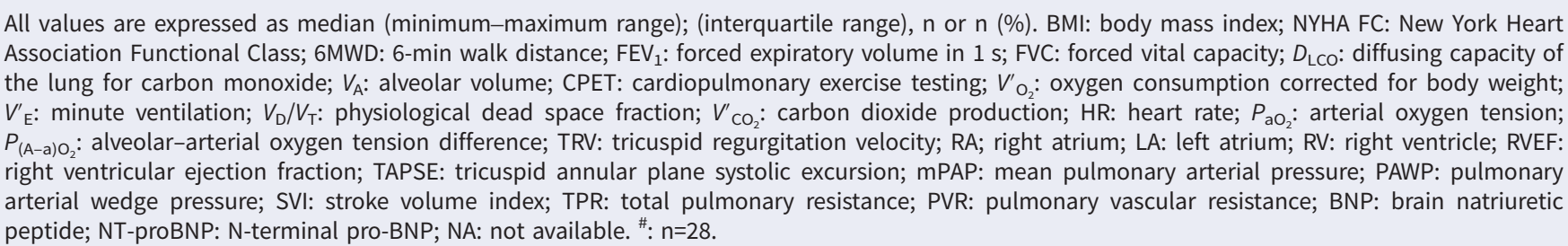 } \\
\hline
\end{tabular}




\begin{tabular}{lccccc}
$\begin{array}{l}\text { TABLE } 2 \\
\text { hypertension }\end{array}$ & Baseline results of investigational cardiopulmonary exercise testing probability score of pulmonary \\
Total score & Likelihood & Subjects & $\begin{array}{c}\text { No pulmonary } \\
\text { hypertension }\end{array}$ & $\begin{array}{c}\text { Exercise pulmonary } \\
\text { hypertension }\end{array}$ & PAH \\
\hline $0-2$ & Unlikely & 31 & $28(90.3)$ & $3(9.7)$ & 0 \\
$3-5$ & Possible & 21 & $11(52.4)$ & $9(42.9)$ & $1(4.8)$ \\
$6-8$ & Likely & 1 & $1(100)$ & 0 & 0 \\
$9-10$ & Very likely & 1 & 0 & 0 & $1(100)$ \\
\hline \multicolumn{7}{l}{ Data are presented as n or n (\%). PAH: pulmonary arterial hypertension. } \\
\hline
\end{tabular}

\section{Description of the screened PAH cases}

The first case was a 26-year-old female included 3 months post-partum. ECG showed right axis deviation (QRS axis $+100^{\circ}$ ) and inverted T-waves in the right pre-cordial leads. 6MWD was $533 \mathrm{~m}$. PFTs were normal except for a low $D_{\text {LCO }}(50 \%$ predicted). Based on the investigational CPET probability score, she was considered as "possible" pulmonary hypertension. Doppler echocardiography showed normal TRV $\left(2 \mathrm{~m} \cdot \mathrm{s}^{-1}\right)$, absence of right atrial or ventricular dilatation and no other sign suggestive of pulmonary hypertension. TAPSE was $25 \mathrm{~mm}$. BNP was normal. RHC revealed pre-capillary pulmonary hypertension at rest (mPAP $26 \mathrm{mmHg}$, PAWP $8 \mathrm{mmHg}$, cardiac output $7.27 \mathrm{~L} \cdot \mathrm{min}^{-1}$, cardiac index $4.38 \mathrm{~L} \cdot \mathrm{min}^{-1} \cdot \mathrm{m}^{-2}$ and PVR 2.5 WU) (table 1) and exercise pulmonary hypertension (mPAP $43 \mathrm{mmHg}$ and TPR 3.6 WU). Because of the absence of symptoms in a subject with PVR $<3$ WU at rest, no PAH therapy was started and a careful follow-up was proposed. After 4 months, the patient had progressed to NYHA FC II and RHC demonstrated haemodynamic deterioration (mPAP $35 \mathrm{mmHg}$, cardiac index $2.39 \mathrm{~L} \cdot \mathrm{min}^{-1} \cdot \mathrm{m}^{-2}$ and PVR 6.8 WU) confirming PAH. Oral dual combination therapy with an endothelin receptor antagonist (ERA) and a phosphodiesterase type 5 inhibitor (PDE5i) was initiated.

The second case was a 78-year-old female with systemic hypertension and type 2 diabetes. ECG showed inverted T-waves in the right pre-cordial leads. 6MWD was $420 \mathrm{~m}$. PFTs were normal apart from reduced $D_{\text {LCO }}(63 \%$ predicted). Based on the investigational CPET probability score, she was considered as "very likely” pulmonary hypertension. Doppler echocardiography showed normal TRV $\left(2.65 \mathrm{~m} \cdot \mathrm{s}^{-1}\right)$, absence of right atrial or ventricular dilatation and no other sign suggestive of pulmonary hypertension. TAPSE was $16 \mathrm{~mm}$. BNP was normal. RHC at rest revealed pre-capillary pulmonary hypertension (mPAP $25 \mathrm{mmHg}$, PAWP $7 \mathrm{mmHg}$, cardiac index $2.8 \mathrm{~L} \cdot \mathrm{min}^{-1} \cdot \mathrm{m}^{-2}$ and PVR $4.4 \mathrm{WU}$ ) (table 1). Oral monotherapy with a PDE5i was initiated.
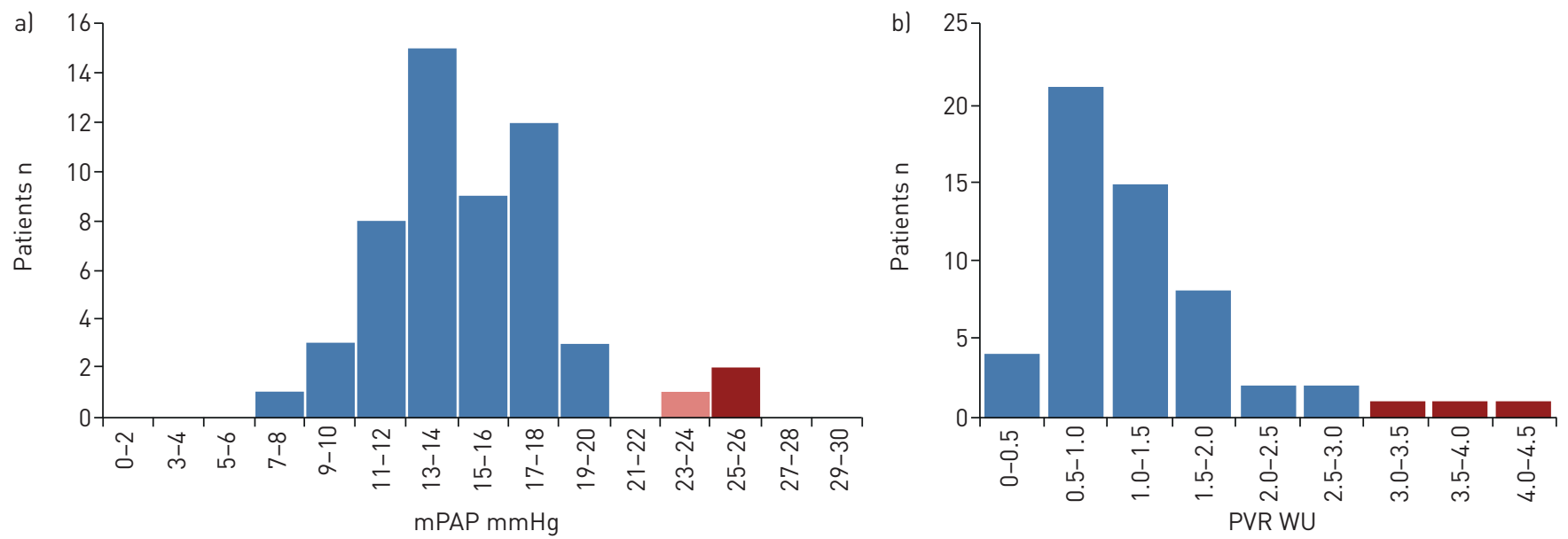

FIGURE 3 Distribution of haemodynamics at baseline among 55 asymptomatic BMPR2 mutation carriers: a) mean pulmonary arterial pressure (mPAP) (dark red: patients with mPAP $\geqslant 25 \mathrm{mmHg}$; light red: $\mathrm{mPAP} 21-24 \mathrm{mmHg}$; blue: $\mathrm{mPAP} \leqslant 20 \mathrm{mmHg}$ ) and b) pulmonary vascular resistance (PVR) (dark red: patients with PVR $>3$ WU; blue: PVR $\leqslant 3$ WU). 
TABLE 3 Comparison of haemodynamics between subjects with normal haemodynamics on exercise and subjects with exercise pulmonary hypertension

\begin{tabular}{|c|c|c|c|}
\hline & $\begin{array}{c}\text { No exercise pulmonary } \\
\text { hypertension }\end{array}$ & $\begin{array}{l}\text { Exercise pulmonary } \\
\text { hypertension" }\end{array}$ & $\mathrm{p}$-value \\
\hline Subjects & 40 & 12 & \\
\hline Female & $18(45)$ & $9(75)$ & 0.07 \\
\hline Age years & 26.9 (18-58); (23.6-41.8) & 58.7 (43.8-67.5); (52.8-64.1) & $<0.0001$ \\
\hline \multicolumn{4}{|l|}{ Haemodynamics at rest } \\
\hline mPAP mmHg & 14 (8-20); (12-16.5) & 16.5 (13-23); (14.5-18) & 0.020 \\
\hline Cardiac index $\mathrm{L} \cdot \mathrm{min}^{-1} \cdot \mathrm{m}^{-2}$ & $3.59(2.62-5.44) ;(3.23-4.11)$ & $3.12(2.20-4.80) ;(2.62-3.63)$ & 0.0226 \\
\hline $\mathrm{SVI} \mathrm{mL} \cdot \mathrm{m}^{-2}$ & 51.0 (32.3-75.6); (45.3-54.4) & 43.9 (32.7-57.9); (37.0-49.5) & 0.0076 \\
\hline PAWP $\mathrm{mmHg}$ & 9 (3-14); (7-11) & $6(2-12) ;(4.5-9.0)$ & 0.036 \\
\hline PVR WU & $0.8(0.2-1.5) ;(0.6-1.2)$ & $1.6(0.6-3.7) ;(1.6-2.3)$ & $<0.0001$ \\
\hline TPR WU & $2.3(1.2-3.7) ;(1.8-2.8)$ & $3.2(2.3-4.8) ;(2.5-3.8)$ & 0.001 \\
\hline \multicolumn{4}{|l|}{$\begin{array}{l}\text { Haemodynamics at peak } \\
\text { exercise }\end{array}$} \\
\hline Workload W & 90 (30-150); (60-100) & 70 (30-100); (55-80) & 0.015 \\
\hline mPAP mmHg & 20 (8-20); (21-29.5) & 40 (34-54); (36.5-47.5) & $<0.0001$ \\
\hline Cardiac index $\mathrm{L} \cdot \mathrm{min}^{-1} \cdot \mathrm{m}^{-2}$ & 8.99 (5.77-11.59); (8.30-9.73) & 6.49 (4.75-8.83); (5.8-7.4) & $<0.0001$ \\
\hline $\mathrm{SVI} \mathrm{mL} \cdot \mathrm{m}^{-2}$ & 68.5 (48.2-94.5); (59.6-77.2) & 53.9 (42.8-66.9); (47.8-59.7) & 0.0002 \\
\hline PAWP $\mathrm{mmHg}$ & 14 (6-25); (12-18) & 25 (20-30); (22.5-26.0) & $<0.0001$ \\
\hline PVR WU & $0.65(0.1-1.4) ;(0.5-0.9)$ & $1.6(0.8-2.3) ;(1.3-1.9)$ & $<0.0001$ \\
\hline TPR WU & $1.6(0.9-3.1) ;(1.3-2.1)$ & $3.55(3-5) ;(3.3-4.7)$ & $<0.0001$ \\
\hline \multicolumn{4}{|l|}{ Long-term follow-up } \\
\hline $\mathrm{PAH}$ & $1(2.4)$ & $2(16.7)$ & \\
\hline \multicolumn{4}{|c|}{$\begin{array}{l}\text { Data are presented as } \mathrm{n}, \mathrm{n}(\%) \text { or median (minimum-maximum range); (interquartile range), unless otherwise } \\
\text { stated. mPAP: mean pulmonary arterial pressure; SVI: stroke volume index; PAWP: pulmonary arterial wedge } \\
\text { pressure; PVR: pulmonary vascular resistance; TPR: total pulmonary resistance; PAH: pulmonary arterial } \\
\text { hypertension. ": pulmonary hypertension at exercise was defined by an increased in mPAP }>30 \mathrm{mmHg} \text { and TPR } \\
>3 \text { WU. }\end{array}$} \\
\hline
\end{tabular}

\section{Two-year mandatory follow-up}

During follow-up, five additional RHCs were performed based on a decrease in $V_{\mathrm{O}_{2}}^{\prime}$ at peak $>20 \%$ (in isolation in three subjects and associated with unexplained dyspnoea in two subjects). Pulmonary hypertension was not diagnosed in these five subjects. Eight subjects did not complete all follow-up visits, including two females because of pregnancy. After delivery, these two females were subsequently followed long-term. Phone calls were made for the subjects who missed follow-up visits: none reported clinical signs suggestive of pulmonary hypertension. During the 2-year initial follow-up, no unscheduled visit was needed and no additional PAH case was diagnosed.

\section{Long-term follow-up}

36 subjects consented to undergo the optional long-term follow-up as part of usual care. A total of 103 visits as of 1 August 2019 (118.8 patient-years of follow-up) were completed as part of long-term follow-up. Thus, 247 follow-up visits (215.6 patient-years) were performed during a follow-up of 47 \pm 27 months for the entire duration of DELPHI-2. The 12 subjects who did not accept clinical long-term follow-up agreed to receive annual phone calls.

Three additional PAH cases were diagnosed 6 years after the initial visit in two females (aged 50 and 73 years) and a 47-year-old male. Characteristics of these patients at PAH diagnosis are presented in table 1 (patients 3, 4 and 5). Patients 4 and 5 were from the same family (aunt and nephew). At the time of PAH diagnosis, one patient was asymptomatic (diagnosed at a scheduled visit) and two were mildly symptomatic NYHA FC II (diagnosed at unscheduled visits), with a delay between symptom onset and $\mathrm{PAH}$ diagnosis of 3 and 6 months, respectively. PAH was associated with mild to moderate functional impact on 6MWD (ranging from 397 to $505 \mathrm{~m}$ ). NT-proBNP concentrations were in the normal range in the asymptomatic case and mildly elevated in the two symptomatic patients. Doppler echocardiography was abnormal with TRV $>2.8 \mathrm{~m} \cdot \mathrm{s}^{-1}$ in the three patients $\left(3.3-4.4 \mathrm{~m} \cdot \mathrm{s}^{-1}\right)$. RHC confirmed PAH with more severe haemodynamic compromise (PVR 7.3-9.2 WU) compared with the cases screened by RHC in the initial phase of the study. Three patients had signs of pulmonary hypertension on ECG, two had "very likely" pulmonary hypertension based on the CPET probability score and the other had a $22 \%$ decrease of 
$V_{\mathrm{O}_{2}}^{\prime}$ at peak (CPET probability score not evaluable because of the absence of arterial blood gases at exercise), and two of them had $D_{\mathrm{LCO}}<70 \%$ predicted.

\section{Incidence of PAH in BMPR2 mutation carriers}

In this cohort, 9.1\% of asymptomatic BMPR2 mutation carriers developed PAH at follow-up with a marked female predominance: $13.8 \%$ (four out of 29) in females and 3.8\% (one out of 26) in males ( $p=0.42$ ). The incidence of PAH in the whole population was $2.3 \%$ per year. The incidence of PAH was higher in females: four females diagnosed with PAH during 114.4 patient-years of follow-up and one male diagnosed with PAH during 101.2 of follow-up (3.5\% and $0.99 \%$ per year, respectively).

At long-term follow-up, two of the 12 subjects with pulmonary hypertension at exercise developed PAH (16.7\%) versus one of the 40 subjects (2.5\%) with normal exercise haemodynamics ( $p=0.25$ ) (figure 2 ).

\section{Characteristics of patients diagnosed with $P A H$ versus subjects without pulmonary hypertension at follow-up}

Complete work-up performed in the five patients with pre-capillary pulmonary hypertension identified no other condition known to be associated with pulmonary hypertension according to the current classification of pulmonary hypertension [1, 2]. Among the five patients diagnosed with PAH in the study, three patients belonged to families with several identified cases of PAH and two patients were relatives from index cases displaying a sporadic form of PAH (figure 4). Compared with subjects without pulmonary hypertension at follow-up ( $\mathrm{n}=50$ ), patients with PAH presented with lower 6MWD (median 420 versus $540 \mathrm{~m}$ ), lower $D_{\text {LCO }}$ (median 52 versus $78 \%$ predicted) and elevated TRV (median 3.3 versus $2.0 \mathrm{~m} \cdot \mathrm{s}^{-1}$ ) at diagnosis. No individual CPET parameter differed individually.

Additional risk factors might have played a role as second hits in patient 1 who developed PAH a few months after pregnancy and in patient 3 who received several chemotherapies for breast cancer, including docetaxel, trastuzumab, bevacizumab, paclitaxel and lapatinib before inclusion, and vinorelbine and trastuzumab emtansine 3 months before onset of symptoms. Patient 4 had a personal history of non-Hodgkin's lymphoma treated 18 years before by chemotherapy and radiotherapy.

\section{Noninvasive screening criteria}

Since NT-proBNP plasma concentrations and Doppler echocardiography were normal in all subjects at inclusion, we assessed the relationship between ECG, $D_{\text {LCO }}$ and CPET parameters with invasive haemodynamics. Table 4 describes the proportion of screened PAH and exercise pulmonary hypertension of unknown significance according to three diagnostic criteria: 1) ECG signs suggestive of pulmonary hypertension, 2) "possible, likely or very likely” CPET score (from 3 to 10 ) and 3) $D_{\text {LCO }}<70 \%$ predicted. Absence of pulmonary hypertension at rest or exercise was seen in $85.7 \%, 80.0 \%, 60.0 \%$ and $0 \%$ of subjects with none, one, two or three of these criteria, respectively (table 4). In the three subjects who met three of these criteria at inclusion, two were screened with PAH and one had exercise pulmonary hypertension. Absence of these three criteria was present in 21 patients (38.1\%) at baseline. All five PAH patients had at least one of these three criteria at the time of diagnosis.

\section{Outcomes of patients diagnosed with $\mathrm{PAH}$}

A total of five BMPR2 mutation carriers (four females and one male) were diagnosed with PAH during the initial screening and long-term follow-up. Table 5 shows the clinical, functional and haemodynamic characteristics of the five PAH patients identified in DELPHI-2 compared with their 31 index PAH cases with BMPR2 mutations. Patients diagnosed via the DELPHI-2 screening programme had markedly better functional capacity and milder haemodynamics compared with index cases diagnosed via routine clinical care.

Four patients were treated with oral dual combination therapy (ERA and PDE5i) and one patient received monotherapy (PDE5i). Evolution and response to specific PAH therapy are presented in table 6. All patients attained or maintained a low-risk profile according to the REVEAL 2.0 score, the ESC/ERS guidelines risk stratification tool and the simplified French PAH risk assessment (table 6) [2, 22, 23]. No death occurred at follow-up, while survival observed in index cases was $90 \%$ and $84 \%$ at 1 and 3 years, respectively (figure 5).

No death occurred in the remaining 50 subjects. Of note, the case of ostium secundum atrial septal defect with mild left-to-right shunt diagnosed during the study was closed based on normal haemodynamics at rest. Haemodynamics at rest and exercise controlled 4 months after closure remained normal. After 6 years of follow-up, the patient has not developed PAH and is doing well. 
Family 1

c. 2617C>T; p.Arg873X

I

II

III

IV

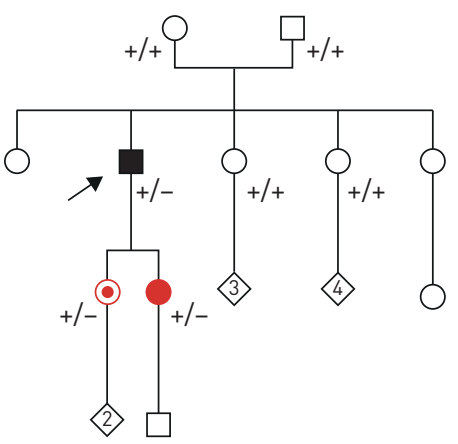

Family 3

c. 1771 C > T; p.Arg591X

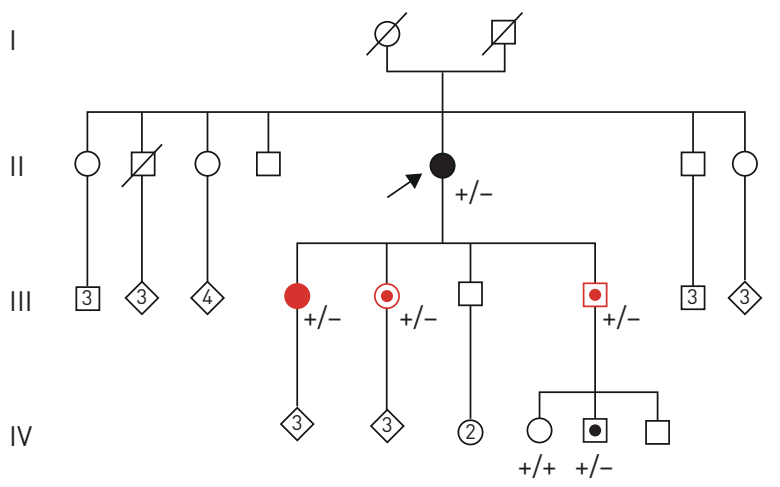

Family 2

c. $961 \mathrm{C}>\mathrm{T} ;$ p.Arg321X

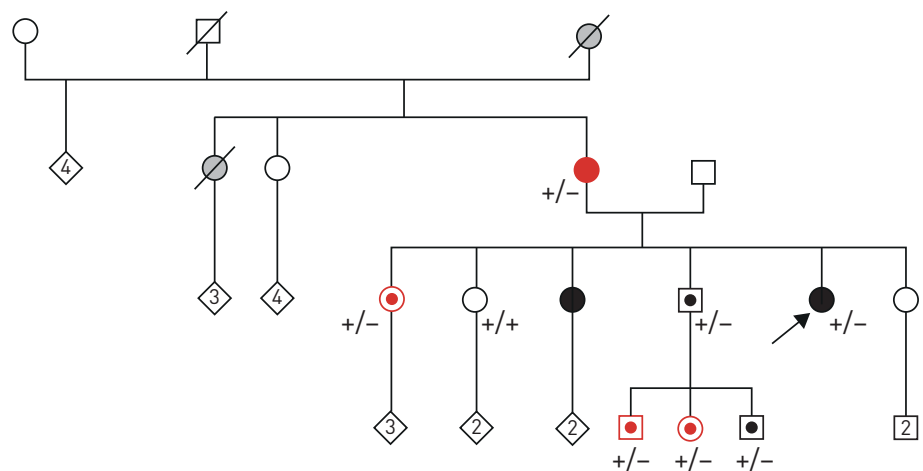

Family 4

c. $1472 \mathrm{G}>\mathrm{A} ;$ p.Arg491GIn

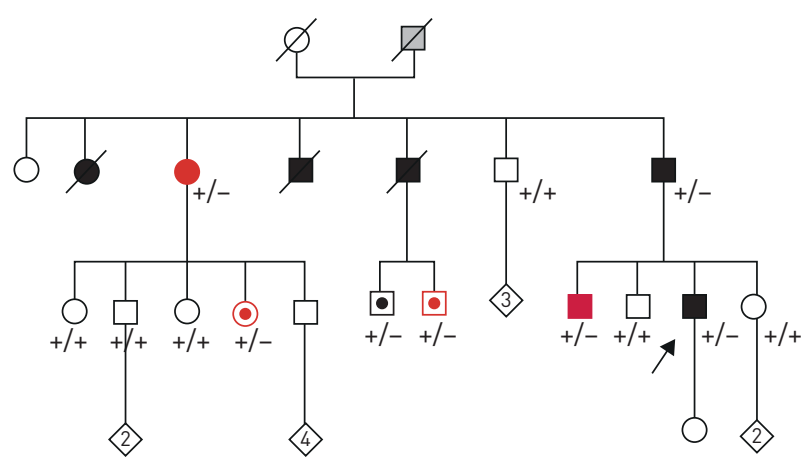

+/+ Mutation noncarriers

+/- BMPR2 mutation carriers

$\square$ PAH patients

$\square$ Suspected PAH patients
BMPR2 mutation carriers who developed PAH during DELPHI-2

- - Asymptomatic BMPR2 mutation carriers followed in DELPHI-2

- Asymptomatic BMPR2 mutation carriers who declined follow-up

FIGURE 4 Family trees of BMPR2 mutation carriers who developed pulmonary arterial hypertension (PAH) during DELPHI-2. Arrows indicate the index case in each family. Patient 1 belongs to family 1 (IIIL), patient 2 belongs to family 2 (II7), patient 3 belongs to family 3 (IIII1), and patients 4 and 5 belong to family 4 (III and IIII1, respectively).

Consequences of the new cut-off values for pulmonary hypertension diagnosis

Using the new cut-off values proposed to define PAH (mPAP > $20 \mathrm{mmHg}$, PAWP $\leqslant 15 \mathrm{mmHg}$ and PVR $\geqslant 3 \mathrm{WU}$ ) [1], no additional case would be diagnosed in our cohort. At baseline, a 67-year-old male presented with mPAP > $20 \mathrm{mmHg}$ but PVR <3 WU (mPAP $23 \mathrm{mmHg}$, PAWP $6 \mathrm{mmHg}$, cardiac output $8.63 \mathrm{~L} \cdot \mathrm{min}^{-1}$ and PVR $2.0 \mathrm{WU}$ ) and a 59-year-old female presented with PVR $\geqslant 3 \mathrm{WU}$ but with mPAP $\leqslant 20 \mathrm{mmHg}$ (mPAP $16 \mathrm{mmHg}$, PAWP $2 \mathrm{mmHg}$, cardiac output $3.8 \mathrm{~L} \cdot \mathrm{min}^{-1}$ and PVR $3.7 \mathrm{WU}$ ). At peak exercise, these subjects had exercise pulmonary hypertension (mPAP 54 and $39 \mathrm{mmHg}$ and TPR 3.4 and 5.0 WU, respectively) associated with an increased PAWP (25 and $21 \mathrm{mmHg}$, respectively). A decrease in PVR was observed at exercise in these two subjects (from 2 to $1.8 \mathrm{WU}$ and from 3.7 to $2.3 \mathrm{WU}$, respectively). These patients did not develop incident PAH 6 years after inclusion in the study.

\section{Discussion}

Early diagnosis of PAH and timely intervention are associated with better long-term outcomes [9-11]. Therefore, increasing awareness of $\mathrm{PAH}$ and promoting strategies to enable early diagnosis are important 
TABLE 4 Diagnosis of pulmonary arterial hypertension (PAH) and exercise pulmonary hypertension according to ECG, cardiopulmonary exercise testing (CPET) probability score and diffusing lung capacity for carbon monoxide $\left(D_{\text {LCO }}\right)$ in asymptomatic relatives at inclusion in DELPHI-2

\begin{tabular}{|c|c|c|c|c|}
\hline & $\begin{array}{c}\text { All } \\
\text { subjects }\end{array}$ & $\begin{array}{l}\text { No pulmonary } \\
\text { hypertension }\end{array}$ & $\begin{array}{l}\text { Exercise pulmonary } \\
\text { hypertension }\end{array}$ & PAH \\
\hline Subjects & 54 & 40 & 12 & 2 \\
\hline \multicolumn{5}{|c|}{ Number of criteria\# } \\
\hline 0 & 21 & $18(85.7)$ & $3(14.3)$ & 0 \\
\hline 1 & 20 & $16(80.0)$ & $4(20.0)$ & 0 \\
\hline 2 & 10 & $6(60.0)$ & $4(40.0)$ & 0 \\
\hline 3 & 3 & 0 & $1(33.3)$ & $2(66.7)$ \\
\hline
\end{tabular}

strategies to improve the outcomes of this severe but treatable condition. This is particularly true in subjects at high risk of developing $\mathrm{PAH}$ such as those with systemic sclerosis or unaffected family members of heritable PAH carrying a BMPR2 mutation [9-11, 24]. Annual screening echocardiography is currently recommended in asymptomatic BMPR2 mutation carriers [2, 4], but the utility and performance of this screening strategy is not known. The DELPHI-2 study aimed to assess the risk of occurrence of PAH in asymptomatic BMPR2 mutation carriers and to evaluate the incorporation of a multimodal screening programme into clinical care for early detection of PAH. BMPR2 mutations have an incomplete penetrance and heritable PAH can occur at any age, which results in a relatively low overall annual incidence of PAH in asymptomatic BMPR2 mutation carriers. Despite this, our prospective cohort study showed, for the first time, that asymptomatic adult BMPR2 mutation carriers can develop incident PAH in a relatively short follow-up time span with an incidence of $2.3 \%$ per year. This is particularly true in females who showed an incidence of $3.5 \%$ versus $0.99 \%$ per year in males. Interestingly, patients diagnosed with PAH in the DELPHI-2 screening programme belonged to families with multiple PAH cases but were also found in relatives of sporadic PAH cases carrying BMPR2 mutations. This result suggests that screening programmes should not be restricted to families with several PAH cases. Some of the cases we report have developed incident PAH after pregnancy or chemotherapy, suggesting the

TABLE 5 Comparison of clinical and haemodynamic characteristics at diagnosis of pulmonary arterial hypertension (PAH) patients identified in DELPHI-2 and the index cases in their family

\begin{tabular}{|c|c|c|c|}
\hline & Index cases & DELPHI-2 PAH patients & $\mathrm{p}$-value \\
\hline Subjects & 31 & 5 & \\
\hline \multicolumn{4}{|l|}{ Clinical characteristics } \\
\hline Female & $22(71)$ & $4(80)$ & 0.90 \\
\hline Age years & 38 (5-63); (26-47) & 50 (26-78); (41-74) & 0.06 \\
\hline \multicolumn{4}{|l|}{ NYHA FC } \\
\hline I & 0 & 3 & $<0.001$ \\
\hline II & 4 & 2 & \\
\hline III & 18 & 0 & \\
\hline IV & 7 & 0 & \\
\hline 6MWD m & $356(0-530) ;(304-400)$ & 420 (397-533); (408-512) & 0.02 \\
\hline \multicolumn{4}{|l|}{ Haemodynamic characteristics } \\
\hline mPAP $\mathrm{mmHg}$ & 58 (45-95); (51.5-72.3) & $29(25-50) ;(25.8-44.8)$ & $<0.001$ \\
\hline Cardiac output L. $\min ^{-1}$ & 3.46 (1.85-5.9); (2.65.9-4.13) & 4.05 (3.27-7.27); (3.77-5.25) & 0.14 \\
\hline Cardiac index $\mathrm{L} \cdot \mathrm{min}^{-1} \cdot \mathrm{m}^{-2}$ & $2.10(1.14-3.7) ;(1.61-2.42)$ & $2.36(1.94-4.38) ;(2.22-3.20)$ & 0.14 \\
\hline PAWP $\mathrm{mmHg}$ & $8(1-19) ;(5-9)$ & $7(5-8) ;(6.5-8)$ & 0.6 \\
\hline PVR WU & 15.4 (7.6-31.8); (12.1-22.1) & $7.3(2.5-9.2) ;(4.0-9.2)$ & 0.001 \\
\hline
\end{tabular}


TABLE 6 Evolution of pulmonary arterial hypertension (PAH) patients at last follow-up according to risk assessment from the REVEAL 2.0 score, the European Society of Cardiology/European Respiratory Society (ESC/ERS) guidelines risk stratification tool and the simplified French PAH risk assessment

\begin{tabular}{|c|c|c|c|c|c|}
\hline & Patient 1 & Patient $2^{\#}$ & Patient 3 & Patient 4 & Patient 5 \\
\hline Delay between diagnosis and assessment months & 71 & 69 & 5 & 6 & 5 \\
\hline PAH therapies & ERA, PDE5i & PDE5i & ERA, PDE5i & ERA, PDE5i & ERA, PDE5i \\
\hline Score at diagnosis & 2 & 3 & 8 & 4 & 5 \\
\hline Score at last follow-up & 4 (low risk) & 4 (low risk) & 5 (low risk) & 2 (low risk) & 3 (low risk) \\
\hline \multicolumn{6}{|l|}{ ESC/ERS guidelines [2] $]^{4}$} \\
\hline Syncope & No & No & No & No & No \\
\hline NYHA FC & II & 1 & II & 1 & II \\
\hline 6MWD m & 587 & 358 & 454 & 490 & 533 \\
\hline \multicolumn{6}{|l|}{ CPET } \\
\hline$V^{\prime} \mathrm{O}_{2}$ at peak $\mathrm{mL} \cdot \mathrm{min}^{-1} \cdot \mathrm{kg}^{-1}(\%$ pred $)$ & NA & NA & NA & $15(81)$ & $25(76)$ \\
\hline$V_{E}^{\prime} / V_{\mathrm{CO}_{2}}^{\prime}$ slope & NA & NA & NA & 40 & 32 \\
\hline \multicolumn{6}{|l|}{ Haemodynamics } \\
\hline RAP $\mathrm{mmHg}$ & 6 & 7 & 5 & 4 & 11 \\
\hline Cardiac index $\mathrm{L} \cdot \mathrm{min}^{-1} \cdot \mathrm{m}^{-2}$ & 2.57 & 2.56 & 2.83 & 2.42 & 2.68 \\
\hline $\mathrm{S}_{\mathrm{vO}_{2}} \%$ & 71 & 68 & 73 & 71 & 71 \\
\hline \multicolumn{6}{|l|}{ Simplified risk assessment [22] } \\
\hline NYHA FC I/II & Yes & Yes & Yes & Yes & Yes \\
\hline $6 \mathrm{MWD}>440 \mathrm{~m}$ & Yes & No & Yes & Yes & Yes \\
\hline $\mathrm{RAP}<8 \mathrm{mmHg}$ & Yes & Yes & Yes & Yes & No \\
\hline Cardiac index $\geqslant 2.5 \mathrm{~L} \cdot \mathrm{min}^{-1} \cdot \mathrm{m}^{-2}$ & Yes & Yes & Yes & No & Yes \\
\hline Low-risk criteria $n$ & 4 & 3 & 4 & 3 & 4 \\
\hline \multicolumn{6}{|c|}{$\begin{array}{l}\text { Data are presented as } n \text {. ERA: endothelin receptor antagonist; PDE5i: phosphodiesterase type } 5 \text { inhibitor; NYHA FC: New York Heart Association } \\
\text { Functional Class; } 6 \text { MWD: } 6 \text {-min walk distance; CPET: cardiopulmonary exercise testing; } V^{\prime} \mathrm{O}_{2}: \text { oxygen consumption; } V_{\mathrm{E}}^{\prime}: \text { minute ventilation; } V^{\prime} \mathrm{CO}_{2} \text { : } \\
\text { carbon dioxide production; NT-proBNP: N-terminal pro-brain natriuretic peptide; RA: right atrium; RAP: right atrial pressure; } S_{\mathrm{vO}}: \text { mixed venous } \\
\text { oxygen saturation; NA: not available. ": for patient 2, haemodynamic reassessment was performed at } 6 \text { months of follow-up; ": green indicates "low } \\
\text { risk" and yellow indicates "intermediate risk" according to the ESC/ERS guidelines. }\end{array}$} \\
\hline
\end{tabular}

potential relevance of second hits for disease to fully evolve in this population. Interestingly, most of the drugs (docetaxel, trastuzumab, bevacizumab and lapatinib) received by the patients who develop PAH have been reported to be associated with drug-induced PAH [25-28]. Chemotherapy exposure did not occur in the 50 relatives without PAH. Using a comprehensive multimodal screening programme, PAH was diagnosed at a relatively early stage, allowing timely initiation of targeted PAH therapy.

PAH can frequently complicate the course of associated conditions such as systemic sclerosis. Indeed, 8-12\% of systemic sclerosis patients will develop PAH with an incidence of $\sim 1 \%$ per year in cohort studies, broadly comparable to the incidence described in DELPHI-2 [29]. Recent PAH screening programmes in systemic sclerosis have underscored the importance of combining a number of modalities to maximise sensitivity, e.g. $D_{\mathrm{LCO}}$, NT-proBNP, ECG and Doppler echocardiography, compared with approaches solely reliant on the use of a single modality, e.g. echocardiography [24, 30]. In DELPHI-2, Doppler echocardiography or BNP/NT-proBNP failed to detect PAH patients in asymptomatic BMPR2 mutation carriers. The two patients screened at inclusion had normal echocardiography with normal TRV, absence of right atrial or ventricular dilatation and absence of other signs suggestive of pulmonary hypertension. Of note, three patients had isolated enlarged right atrial surface area $\left(>18 \mathrm{~cm}^{2}\right)$ on echocardiography, but none of these had PAH at baseline RHC or during follow-up, suggesting that these cases were "false-positive" cases. This study demonstrated that RHC is effective to diagnose PAH in asymptomatic BMPR2 mutation carriers. However, because of its invasive nature and associated morbidity (1.1\%) and mortality (0.055\%) rates [31], RHC cannot be considered a routine screening examination that is used repeatedly, but should be reserved for when noninvasive investigations raise suspicion of $\mathrm{PAH}$ or in high-risk situations to 


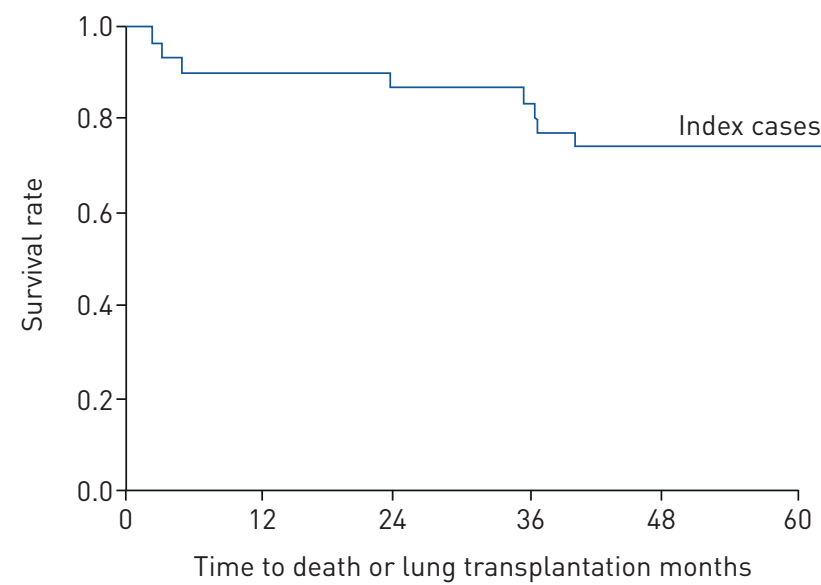

At risk $\mathrm{n}: 31$

28

27

24

21

20

FIGURE 5 Time to death or lung transplantation in index cases of the 31 families of subjects included in DELPHI- 2 .

confirm diagnosis. Combination of three parameters based on ECG, $D_{\text {LCO }}$ and CPET probability score (table 4) may be of interest to identify PAH patients. The absence of these three criteria was helpful to exclude the diagnosis of PAH in this high-risk population and to avoid unnecessary RHC. Moreover, CPET was also abnormal in all screened PAH patients, highlighting the importance of measuring indicators of exercise limitation. Since no CPET value alone is conclusive of PAH, we used a predefined probability score of pulmonary hypertension on CPET adapted from previous published studies [15-20]. Refinements and validation of CPET probability scores suggestive of pulmonary hypertension should be encouraged in future studies evaluating early diagnosis of PAH. It is therefore likely that the current recommendation of annual echocardiography on its own will be outperformed by a comprehensive multimodal approach in asymptomatic BMPR2 mutation carriers. In the long-term follow-up, echocardiography and NT-proBNP were useful in detecting mildly symptomatic PAH with more severe haemodynamic impairment. In clinical practice, screening is often extended to include mildly symptomatic patients and our data suggest that echocardiography remains a useful screening test in this setting [30, 32, 33].

Previous findings that BMPR2 mutation carriers have a worse survival suggest that screening for mutations in unaffected relatives followed by a screening and early detection structured programme may improve long-term outcomes. Our study shows that all screened PAH patients were less severe than the usual heritable PAH cases [7, 8]. This is highlighted by the relatively mild invasive haemodynamic findings of BMPR2 carriers diagnosed via DELPHI-2 compared with index BMPR2 carriers who were diagnosed routinely due to the presence of symptoms (table 5). In addition, all were successfully treated with oral monotherapy or dual oral combination therapy with the maintenance of "low-risk status" on therapy, which is associated with survival $>95 \%$ at 5 years based on current registry data (table 6) [22, 23].

Of note, one asymptomatic patient did not completely fulfil the current definition of PAH at the time of screening (PVR <3 WU). According to current guidelines [2], she was not treated but progressed rapidly to moderate PAH within 4 months (NYHA FC II, mPAP $35 \mathrm{mmHg}$ and PVR 6.8 WU). The 2018 Sixth World Symposium on Pulmonary Hypertension provided an opportunity to discuss the haemodynamic definition of pulmonary vascular diseases [1]. This case illustrates that PVR ranging between 2 and 3 WU in the high-risk population of BMPR2 mutation carriers might represent an early abnormal haemodynamic status, associated with disease progression and clinical outcomes [1, 34].

As in systemic sclerosis [24], our study suggests that exercise pulmonary hypertension may be a possible early marker of pulmonary vascular remodelling in BMPR2 mutation carriers. Indeed, $16.7 \%$ of the 12 subjects with exercise pulmonary hypertension at inclusion subsequently developed PAH during long-term follow-up versus $2.5 \%$ among the 40 subjects with normal exercise haemodynamics. Exercise pulmonary hypertension in this population requires careful phenotyping in order to distinguish the subset of patients with early pulmonary vascular disease from the highly prevalent left heart disease population, especially in older subjects and/or those with cardiovascular comorbidities. These results are in accordance with 
previous studies based on echocardiography during exercise showing that an abnormal haemodynamic response occurred significantly more often in relatives of PAH, particularly for those carrying a BMPR2 mutation [35, 36]. Interestingly, HinderhOFER et al. [37] reported in a large family of BMPR2 mutation carriers that the two members who manifested with PAH during follow-up displayed an abnormal haemodynamic response during exercise at baseline assessment. Nevertheless, our results open up research perspectives on the relevance of this assessment to identify a subpopulation at high risk of developing PAH. Current multicentre studies analysing cohorts of subjects with exercise RHC will provide insights into the clinical relevance of exercise haemodynamics and how best to discriminate between pre- and post-capillary causes of exercise pulmonary hypertension [21].

Because of the relatively high penetrance of PAH in BMPR2 mutation carriers, we strongly believe that genetic and reproductive counselling should be proposed to all females of childbearing age in order to explain the potential risk of PAH development during pregnancy and disease transmission to offspring. During pregnancy, we proposed a specific follow-up including monthly Doppler echocardiography during the second and third trimesters followed by a complete assessment within 3 months of delivery. In France, pre-implantation diagnosis can be offered to BMPR2 mutation carriers in order to avoid transmission to the offspring. However, to date, pre-implantation diagnosis has not been proposed for females who carry a BMPR2 mutation, because of the risk of PAH development during pregnancy and the unknown effects of ovarian stimulation in females with a BMPR2 mutation.

Our study has limitations. First, despite nationwide recruitment in a high-volume reference centre, the number of detected incident PAH was relatively small. However, all screened subjects were carefully investigated, including an initial RHC. In addition, all subjects were followed for at least 2 years and longer-term follow-up data were available up to 7 years, with no loss to follow-up and more than 200 patient-years of analysis. Long-term follow-up of BMPR2 mutation carriers supported by the French Referral Centre for Pulmonary Hypertension is still ongoing and may bring future information on this high-risk population. Second, other promising modalities such as cardiac magnetic resonance or exercise Doppler echocardiography could be of interest [2, 21, 35, 36]. Whether these examinations are superior to conventional tests such as ECG, $D_{\text {LCO }}$, NT-proBNP, echocardiography and CPET remains to be demonstrated. Our cohort study showed that our multimodality screening approach using commonly available investigations allowed early diagnosis of PAH. It should be acknowledged that early pulmonary vascular disease may be present in patients with lower values of mPAP and PVR than the thresholds used to define PAH in this study. DELPHI-2 was performed before the proposal of the new PAH definition [1], but applying the new definition did not identify any additional PAH cases. Definite conclusions on the consequences of a screening programme on long-term outcome are not possible unless a randomised controlled study is performed comparing patients diagnosed via screening versus patients diagnosed via routine care. Even in the systemic sclerosis population, which is broader, such a study has not been performed and is unlikely to be ever performed. The psychological impact of participating in a long-term genetic screening programme remains to be assessed. Although the mean \pm SD age of occurrence of PAH in BMPR2 mutation carriers is $35.4 \pm 14.8$ years [8], PAH due to BMPR2 mutation can occur in children [38]. Predictive genetic testing for children remains a matter of debate in the absence of preventive treatments available for PAH. Furthermore, no genetic testing is currently offered in France for asymptomatic children who are at risk for carrying a PAH-causing mutation [12]. This allows individuals to make a choice once they reach adulthood to make an informed decision regarding genetic testing. Thus, according to French laws on bioethics, this study was restricted to adults and it is difficult to extrapolate our results to the paediatric population. Lastly, we cannot exclude that lead-time bias or length-time bias might have contributed to the observed response to oral therapy and maintenance of low-risk status at last follow-up.

In conclusion, DELPHI-2 represents the first study to systematically examine screening for PAH in asymptomatic BMPR2 mutation carriers. We demonstrate that asymptomatic BMPR2 mutation carriers have a significant risk of developing incident $\mathrm{PAH}$ ranging from $0.99 \%$ per year in males to $3.5 \%$ per year in females. Data from DELPHI-2 indicate that a multimodal screening programme followed by yearly careful follow-up may be implemented in clinical practice in order to allow early detection and treatment of PAH in BMPR2 mutation carriers. International multicentre studies are needed to confirm that refined multimodal screening programmes with regular follow-up allow early detection of PAH.

Acknowledgements: The authors thank all patients, relatives, physicians and healthcare professionals from the French Pulmonary Hypertension Reference Network (PulmoTension). The authors thank the Clinical Research Unit Paris Sud (AP-HP, Hôpital Bicêtre, Le Kremlin-Bicêtre, France) for monitoring and coordinating this study.

This study is registered at ClinicalTrials.gov with identifier number NCT01600898. 
Conflict of interest: D. Montani reports grants and personal fees from Actelion and Bayer, personal fees from GlaxoSmithKline, Pfizer, Chiesi, Boehringer and Incyte Biosciences France, grants, personal fees and nonfinancial support from MSD, nonfinancial support from Acceleron, outside the submitted work. B. Girerd has nothing to disclose. X. Jaïs reports grants from Bayer, grants and personal fees from MSD, grants, personal fees and nonfinancial support from Actelion/Janssen, outside the submitted work. P. Laveneziana reports personal fees from Novartis France and Chiesi France, outside the submitted work. E.M.T. Lau reports grants and personal fees from Actelion and GlaxoSmithKline, outside the submitted work. A. Bouchachi has nothing to disclose. S. Hascoët reports grants and personal fees from Abbott, outside the submitted work. S. Gunther has nothing to disclose. L. Godinas has nothing to disclose. F. Parent has nothing to disclose. C. Guignabert has nothing to disclose. A. Beurnier has nothing to disclose. D. Chemla has nothing to disclose. P. Hervé has nothing to disclose. M. Eyries has nothing to disclose. F. Soubrier has nothing to disclose. G. Simonneau reports personal fees from Bayer and Acceleron, personal fees and nonfinancial support from MSD, outside the submitted work. O. Sitbon reports grants, personal fees and nonfinancial support from Actelion Pharmaceuticals, personal fees from Acceleron Pharmaceuticals, AOP Orphan, Ferrer and Gossamer Bio, grants and personal fees from Bayer HealthCare and MSD, grants from GlaxoSmithKline, outside the submitted work. L. Savale reports personal fees and nonfinancial support from Actelion and Bayer, grants, personal fees and nonfinancial support from GlaxoSmithKline, nonfinancial support from MSD, outside the submitted work. M. Humbert reports grants, personal fees and nonfinancial support from GlaxoSmithKline, personal fees from AstraZeneca, Novartis, Roche, Sanofi, Teva and Merck, grants and personal fees from Acceleron, Actelion and Bayer, outside the submitted work.

Support statement: The DELPHI-2 study (NCT01600898) was funded by the French Ministry of Social Affairs and Health (PHRC P100175) and supported by the French Pulmonary Hypertension Patient Association "HTaPFrance", Chancellerie des Universités, Legs Poix, France, Pulmonary Hypertension Grants Program 2013 from Bayer and the European Respiratory Society (grant LTRF-2013-1592). Funding information for this article has been deposited with the Crossref Funder Registry.

\section{References}

1 Simonneau G, Montani D, Celermajer DS, et al. Haemodynamic definitions and updated clinical classification of pulmonary hypertension. Eur Respir J 2019; 53: 1801913.

2 Galiè N, Humbert M, Vachiery J-L, et al. 2015 ESC/ERS Guidelines for the diagnosis and treatment of pulmonary hypertension: The Joint Task Force for the Diagnosis and Treatment of Pulmonary Hypertension of the European Society of Cardiology (ESC) and the European Respiratory Society (ERS). Eur Respir J 2015; 46: 903-975.

3 Humbert M, Guignabert C, Bonnet S, et al. Pathology and pathobiology of pulmonary hypertension: state of the art and research perspectives. Eur Respir J 2019; 53: 1801887.

4 Galié N, Humbert M, Vachiery J-L, et al. 2015 ESC/ERS Guidelines for the diagnosis and treatment of pulmonary hypertension - web addenda. The Joint Task Force for the Diagnosis and Treatment of Pulmonary Hypertension of the European Society of Cardiology (ESC) and of the European Respiratory Society (ERS). Eur Heart J 2016; 37: 67-119.

5 Larkin EK, Newman JH, Austin ED, et al. Longitudinal analysis casts doubt on the presence of genetic anticipation in heritable pulmonary arterial hypertension. Am J Respir Crit Care Med 2012; 186: 892-896.

6 Morrell NW, Aldred MA, Chung WK, et al. Genetics and genomics of pulmonary arterial hypertension. Eur Respir J 2019; 53: 1801899.

7 Sztrymf B, Coulet F, Girerd B, et al. Clinical outcomes of pulmonary arterial hypertension in carriers of BMPR2 mutation. Am J Respir Crit Care Med 2008; 177: 1377-1383.

8 Evans JDW, Girerd B, Montani D, et al. BMPR2 mutations and survival in pulmonary arterial hypertension: an individual participant data meta-analysis. Lancet Respir Med 2016; 4: 129-137.

9 Humbert M, Yaici A, de Groote P, et al. Screening for pulmonary arterial hypertension in patients with systemic sclerosis: clinical characteristics at diagnosis and long-term survival. Arthritis Rheum 2011; 63: 3522-3530.

10 Galiè N, Rubin L, Hoeper M, et al. Treatment of patients with mildly symptomatic pulmonary arterial hypertension with bosentan (EARLY study): a double-blind, randomised controlled trial. Lancet 2008; 371: 2093-2100.

11 Lau EMT, Humbert M, Celermajer DS. Early detection of pulmonary arterial hypertension. Nat Rev Cardiol 2015; 12: 143-155.

12 Girerd B, Montani D, Jaïs X, et al. Genetic counselling in a national referral centre for pulmonary hypertension. Eur Respir J 2016; 47: 541-552.

13 Herve P, Lau EM, Sitbon O, et al. Criteria for diagnosis of exercise pulmonary hypertension. Eur Respir J 2015; 46: 728-737.

14 Naeije R, Vanderpool R, Dhakal BP, et al. Exercise-induced pulmonary hypertension: physiological basis and methodological concerns. Am J Respir Crit Care Med 2013; 187: 576-583. 
15 Laveneziana P, Garcia G, Joureau B, et al. Dynamic respiratory mechanics and exertional dyspnoea in pulmonary arterial hypertension. Eur Respir J 2013; 41: 578-587.

16 Laveneziana P, Humbert M, Godinas L, et al. Inspiratory muscle function, dynamic hyperinflation and exertional dyspnoea in pulmonary arterial hypertension. Eur Respir J 2015; 45: 1495-1498.

17 Weatherald J, Sattler C, Garcia G, et al. Ventilatory response to exercise in cardiopulmonary disease: the role of chemosensitivity and dead space. Eur Respir J 2018; 51: 1700860.

18 Yasunobu $\mathrm{Y}$, Oudiz RJ, Sun X-G, et al. End-tidal $P_{\mathrm{CO}_{2}}$ abnormality and exercise limitation in patients with primary pulmonary hypertension. Chest 2005; 127: 1637-1646.

19 Higashi A, Dohi Y, Yamabe S, et al. Evaluation of end-tidal $\mathrm{CO}_{2}$ pressure at the anaerobic threshold for detecting and assessing pulmonary hypertension. Heart Vessels 2017; 32: 1350-1357.

20 Farina S, Bruno N, Agalbato C, et al. Physiological insights of exercise hyperventilation in arterial and chronic thromboembolic pulmonary hypertension. Int J Cardiol 2018; 259: 178-182.

21 Kovacs G, Herve P, Barbera JA, et al. An official European Respiratory Society statement: pulmonary haemodynamics during exercise. Eur Respir J 2017; 50: 1700578.

22 Boucly A, Weatherald J, Savale L, et al. Risk assessment, prognosis and guideline implementation in pulmonary arterial hypertension. Eur Respir J 2017; 50: 1700889.

23 Benza RL, Gomberg-Maitland M, Elliott CG, et al. Predicting survival in patients with pulmonary arterial hypertension: the REVEAL risk score calculator 2.0 and comparison with ESC/ERS-based risk assessment strategies. Chest 2019; 156: 323-337.

24 Coghlan JG, Denton CP, Grünig E, et al. Evidence-based detection of pulmonary arterial hypertension in systemic sclerosis: the DETECT study. Ann Rheum Dis 2014; 73: 1340-1349.

25 Ranchoux B, Günther S, Quarck R, et al. Chemotherapy-induced pulmonary hypertension: role of alkylating agents. Am J Pathol 2015; 185: 356-371.

26 Kwon Y, Gomberg-Maitland M, Pritzker M, et al. Telangiectasia and pulmonary arterial hypertension following treatment with trastuzumab emtansine: a case report. Chest 2016; 149: e103-e105.

27 Liotta M, Rose PG, Escobar PF. Pulmonary hypertension in two patients treated with bevacizumab for recurrent ovarian cancer. Gynecol Oncol 2009; 115: 308-309.

28 Alkhatib Y, Albashaireh D, Al-Aqtash T, et al. The role of tyrosine kinase inhibitor 'Lapatinib' in pulmonary hypertension. Pulm Pharmacol Ther 2016; 37: 81-84.

29 Hachulla E, de Groote P, Gressin V, et al. The three-year incidence of pulmonary arterial hypertension associated with systemic sclerosis in a multicenter nationwide longitudinal study in France. Arthritis Rheum 2009; 60: 1831-1839.

30 Khanna D, Gladue H, Channick R, et al. Recommendations for screening and detection of connective tissue disease-associated pulmonary arterial hypertension. Arthritis Rheum 2013; 65: 3194-3201.

31 Hoeper MM, Lee SH, Voswinckel R, et al. Complications of right heart catheterization procedures in patients with pulmonary hypertension in experienced centers. J Am Coll Cardiol 2006; 48: 2546-2552.

32 Hachulla E, Gressin V, Guillevin L, et al. Early detection of pulmonary arterial hypertension in systemic sclerosis: a French nationwide prospective multicenter study. Arthritis Rheum 2005; 52: 3792-3800.

33 Parent F, Bachir D, Inamo J, et al. A hemodynamic study of pulmonary hypertension in sickle cell disease. $N$ Engl J Med 2011; 365: 44-53.

34 Maron BA, Brittan EL, Hess E, et al. The association between pulmonary vascular resistance and clinical outcomes in patients with pulmonary hypertension. Lancet Respir Med 2020; 8: 873-884.

35 Grünig E, Janssen B, Mereles D, et al. Abnormal pulmonary artery pressure response in asymptomatic carriers of primary pulmonary hypertension gene. Circulation 2000; 102: 1145-1150.

36 Grünig E, Weissmann S, Ehlken N, et al. Stress Doppler echocardiography in relatives of patients with idiopathic and familial pulmonary arterial hypertension: results of a multicenter European analysis of pulmonary artery pressure response to exercise and hypoxia. Circulation 2009; 119: 1747-1757.

37 Hinderhofer K, Fischer C, Pfarr N, et al. Identification of a new intronic BMPR2-mutation and early diagnosis of heritable pulmonary arterial hypertension in a large family with mean clinical follow-up of 12 years. PLoS One 2014; 9: e91374.

38 Eyries M, Montani D, Nadaud S, et al. Widening the landscape of heritable pulmonary hypertension mutations in paediatric and adult cases. Eur Respir J 2019; 53: 1801371. 